\title{
Enhanced and co-ordinated movement of the hamster oviduct during the periovulatory period
}

\author{
D. E. Battalia and R. Yanagimachi \\ Department of Anatomy and Reproductive Biology, University of Hawaii School of Medicine, \\ Honolulu, Hawaii 96822, U.S.A.
}

\begin{abstract}
Summary. The movement of the hamster oviduct in vivo was examined after injection of a small quantity of India ink into the lowermost region of the isthmus. An active and co-ordinated movement of both the isthmus and ampulla that caused a rapid transport of the ink to the upper ampulla (and eventually to the ovarian bursa) was observed shortly before, during and within a few hours after ovulation. During the rest of the oestrous cycle, no ink was transported to the upper ampulla despite active contractile movement by the isthmus. These observations suggest that the oviduct as a whole exhibits an efficient contractile movement suited for sperm transport only during the periovulatory period.
\end{abstract}

\section{Introduction}

During copulation, spermatozoa are deposited in the vagina (e.g. rabbit and man) or the uterus (e.g. rodents and pig). From these points of deposition the spermatozoa must migrate to the site of fertilization (usually the ampullary region of the oviduct) to effect fertilization. It was once thought that the innate movement of the spermatozoa was wholly responsible for this migration. More recent studies, however, have shown that the motility of the female genital tract, not of the spermatozoa, plays the major role in sperm transport. The innate movement of the spermatozoa appears to be of critical importance only in passing through structural barriers such as the cervix (Moghissi, Dabich, Levine \& Neuhaus, 1964) and possibly the utero-tubal junction (Leonard \& Perlman, 1949).

In the past, numerous studies have been published dealing with the manner of sperm transport through the cervix and uterus (for reviews, see Hartman, 1957; Bishop, 1961; Blandau, 1969; Bedford, 1970; Davajan, Nakamura \& Kharma, 1970). However, only sparse information is available on the manner and mechanisms of sperm transport through the oviduct. According to Larks, Larks, Hoffer \& Charlson (1971), goat oviducts display pronounced electrical activity during the period of oestrus, which probably reflects increased muscular contractions. The mesosalpinx also exhibits increased muscular activity during the period of ovulation (Halbert \& Conrad, 1975). It has been repeatedly reported that the oviducts of animals mated shortly after ovulation transport the spermatozoa considerably faster than those of animals mated several hours before ovulation (Braden \& Austin, 1964; Yanagimachi \& Chang, 1963; Turnbull, 1966; Yanagimachi \& Mahi, 1976; Shalgi \& Kraicer, 1978). Blandau \& Gaddum-Rosse (1974) demonstrated in vitro that stained oil injected through the utero-tubal junction of preovulatory pigs was propelled toward the ampullary-isthmic junction by antiperistaltic contractions within 5 to $10 \mathrm{sec}$. Oil was recurrently transported through the ampulla and expelled from the infundibulum by a similar mechanism. Similar observations have been made in the oestrous rat (Blandau, 1978). These studies all seem to indicate an increased activity of the oviduct and its supporting tissue (the mesosalpinx) about the time of ovulation. We have studied the nature of this activity in the oviduct of the hamster in vivo. 


\section{Materials and Methods}

Adult virgin golden hamster females weighing 100 to $140 \mathrm{~g}$ were used. They were raised under controlled light cycles (06:00-19:00 h light) and individually caged for at least 1 week before the experiments. The oestrous cycle of each female was determined as described by Orsini (1961) except that the day of ovulation was considered to be Day 1 of the cycle. The general events occurring during the oestrous cycle and the times of observations are indicated in Text-fig. 1.

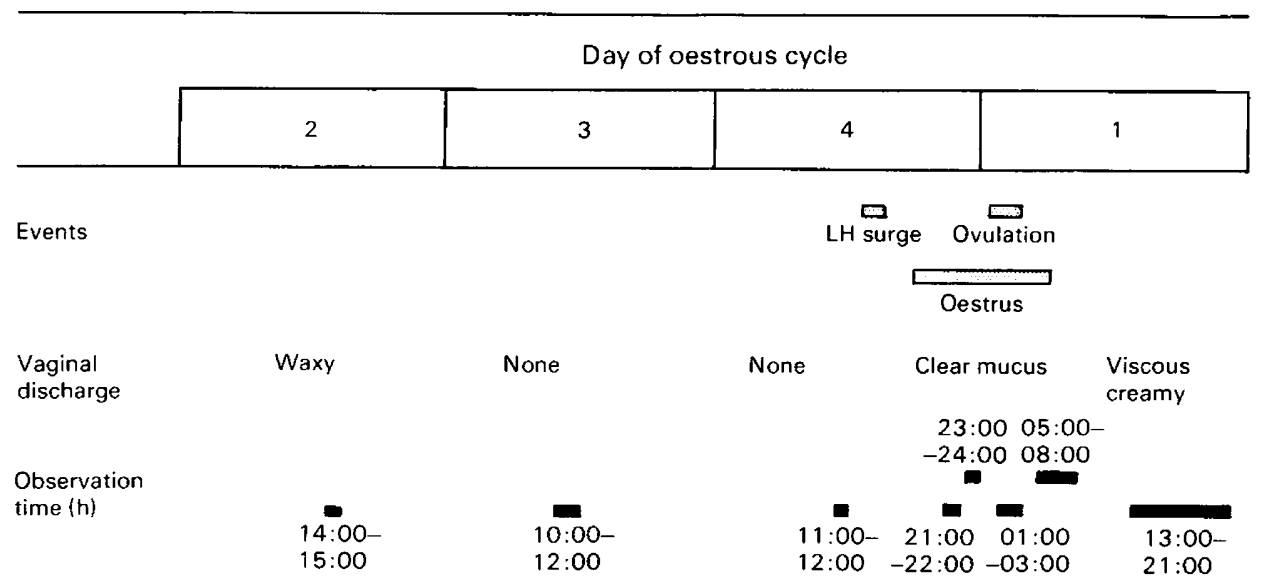

Text-fig. 1. Events occurring during the oestrous cycle of the hamster and periods during which oviduct movement was observed. The LH surge occurs at 14:30-17:30 h (Turgeon \& Greenwald, 1972), and ovulation at 01:00-04:00 h (Austin, 1956; Strauss, 1956) or 00:0002:00 h (Ward, 1946; Norman \& Greenwald, 1972). Oestrus occurs at about 18:00-06:00 h if the animals are not mated.

Anaesthesia was induced and maintained with methoxyflurane vapour (Metofane: PitmanMoore Inc., Fort Washington, Pennsylvania). Our preliminary studies have shown that intrauterine insemination of oestrous females kept under methoxyflurane anaesthesia for 3-4 h resulted in normal fertilization of about $95 \%$ of the ova, indicating that the anaesthetic employed does not affect fertilization or, probably, the activity of the female genital tract.

After induction of anaesthesia, a $4 \mathrm{~cm}$ skin incision was made, starting above the vertebrae midway between the last rib and the illiac crest and running perpendicular to the longitudinal axis of the animal. A $7 \mathrm{~mm}$ incision was then made in the body wall musculature under the midpoint of the skin incision approximately over the position of the ovary. Using blunt forceps, the fat pad surrounding the ovary was gently pulled through the incision with care being taken not to touch the ovarian capsule, oviduct, and uterus. The fat pad was tacked to the fascia over the vertebrae using 2-3 ligatures of 5-0 silk thread. In so doing, the oviduct and upper part of the uterus were pulled through the body wall musculature and exposed to view. The lip of the polypropylene perfusion collar (Text-fig. 2) was then implanted under the skin and sutured and sealed by a purse-string suture of 2-0 silk thread around the skin incision. Locke's solution (in $\mathrm{mg} / 100 \mathrm{ml}: 900 \mathrm{NaCl}, 42 \mathrm{KCl}, 24 \mathrm{CaCl}_{2}, 20 \mathrm{NaHCO}_{3}$ ) was circulated at $3 \mathrm{ml} / \mathrm{min}$ through the perfusion collar and the oviduct was viewed through a stereo-dissecting microscope (Text-fig. 2). The temperature of the hot plate was adjusted so that the saline was at $37^{\circ} \mathrm{C}$ as it reached the collar. About $20 \mathrm{~min}$ after saline circulation was begun, approximately $0 \cdot 2-0.3 \mu \mathrm{l}$ India ink was injected with a micropipette into the isthmus immediately anterior to its intramural segment. The ink used had been previously dialysed extensively against Tyrode's solution (in $\mathrm{mg} / 100 \mathrm{ml}: 800$ 
$\mathrm{NaCl}, 20 \mathrm{KCl}, 20 \mathrm{CaCl}_{2}, 10 \mathrm{MgCl}_{2} \cdot 6 \mathrm{H}_{2} \mathrm{O}, 5 \mathrm{NaH}_{2} \mathrm{PO}_{4} \cdot \mathrm{H}_{2} \mathrm{O}, 100 \mathrm{NaHCO}_{3}$ ). The behaviour of the ink in the tract and the length of time it took to reach various regions of the tract were observed and recorded. Observations in each animal lasted 1-2 h.

Statistical analysis of the data was performed by using Student's $t$ test.

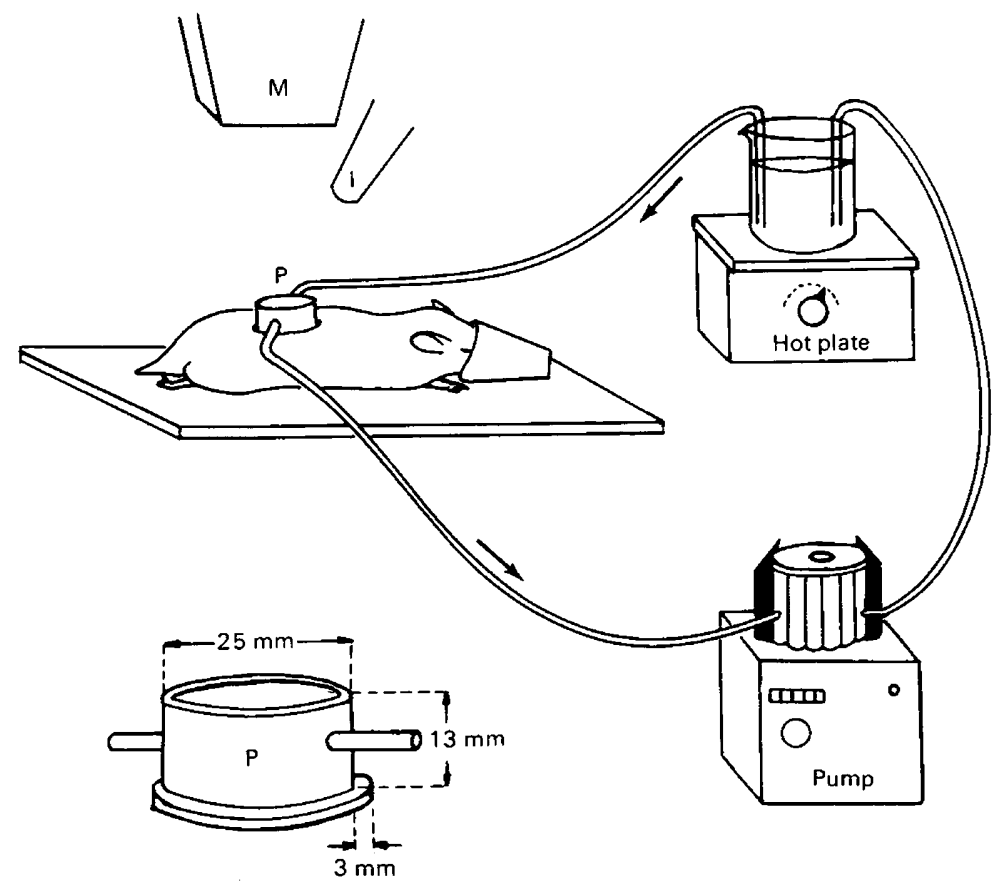

Text-fig. 2. The apparatus used for observations of oviduct motility. As warm Locke's saline was circulated through the perfusion collar (P), the oviduct, bathed in saline, was illuminated (I) and viewed through a stereomicroscope $(\mathrm{M})$.

\section{Observations}

The hamster oviduct is a highly tortuous tube measuring about $40 \mathrm{~mm}$ in length when carefully uncoiled. The ampullary segment of the oviduct is characterized by a relatively large diameter lumen and highly developed longitudinal folds of epithelial mucosa. The isthmic segment has a markedly narrower lumen than the ampulla. The ovarian end of the ampulla, the infundibulum, opens into the periovarian bursa, which is completely surrounded by the ovarian capsule (Clewe, 1965). The uterine end of the isthmus connects with the uterus through the intrauterine segment, the utero-tubal junction (Yanagimachi \& Chang, 1963).

Table 1 summarizes the results of the experiments. When the ink was injected on Days 2, 3, and at 11:00-12:00 h of Day 4, it remained as a small bolus within the isthmus throughout the observation periods. The ink was not static, however. It moved in a to-and-fro manner with the peristaltic contractions of the isthmus. In no instance did the contractions force the ink beyond the mid-isthmus.

The behaviour of the ink injected at 21:00-22:00 $\mathrm{h}$ of Day 4 (soon after the onset of oestrus) was similar to that described above in that the ink remained in the isthmus, but it spread throughout the length of the isthmus. Three of the five females examined had been mated with vasectomized males before the observations, but the results were the same as with 2 non-mated females. Hence these two groups have been pooled in Table 1. 
Table 1. Time (mean \pm s.e.m.) required for India ink to reach the ampulla and ovarian bursa after injection into the lower isthmus of unmated and mated $(\mathrm{M}, 1 \mathrm{~h}$ before surgery) hamsters

\begin{tabular}{|c|c|c|c|c|c|}
\hline \multirow{2}{*}{$\begin{array}{l}\text { Day of } \\
\text { oestrous } \\
\text { cycle }\end{array}$} & \multirow{2}{*}{$\begin{array}{l}\text { Time of } \\
\text { observation } \\
\text { (h) }\end{array}$} & \multirow{2}{*}{$\begin{array}{l}\text { No. of } \\
\text { animals } \\
\text { examined }\end{array}$} & \multicolumn{3}{|c|}{ Time (sec) required for the ink to reach: } \\
\hline & & & Lower ampulla & Upper ampulla & Ovarian bursa \\
\hline 2 & $14: 00-15: 00$ & 3 & - & - & - \\
\hline 3 & $10: 00-12: 00$ & 3 & - & - & - \\
\hline & $11: 00-12: 00$ & 3 & - & - & - \\
\hline & $21: 00-22: 00$ & 5 & - & - & - \\
\hline & $23: 00-24: 00$ & 4 & $238 \cdot 0 \pm 13 \cdot 0^{*}$ & $539.0 \pm 22.5 \dagger$ & - \\
\hline & $23: 00-24: 00$ & $5(\mathrm{M})$ & $41.0 \pm 9.7^{*}$ & $73.0 \pm 14.3 \dagger$ & - \\
\hline \multirow[t]{5}{*}{1} & $01: 00-03: 00$ & 4 & $19 \cdot 0 \pm 3.6$ & $40 \cdot 0 \pm 4 \cdot 1$ & $159 \cdot 0 \pm 22 \cdot 5$ \\
\hline & $01: 00-03: 00$ & $5(M)$ & $15.6 \pm 2.8$ & $24.2 \pm 5.7$ & $157.5 \pm 11.1$ \\
\hline & $05: 00-06: 00$ & 4 & $21 \cdot 0 \pm 5.5$ & $62.5 \pm 7.5$ & - \\
\hline & $07: 00-08: 00$ & 3 & 二 & 二- & - \\
\hline & $13: 00-21: 00$ & 5 & - & - & - \\
\hline
\end{tabular}

* Significantly different, $P<0.01$ (Student's $t$ test).

$\dagger$ Significantly different, $P<0.01$ (Student's $t$ test).

At 23:00-24:00 h on Day 4 (shortly before ovulation), the ink was transported to the ampulla in the mated and non-mated females. The mean times required for the ink to reach the upper region of the ampulla were $539 \mathrm{sec}$ in non-mated animals and $73 \mathrm{sec}$ in mated animals $(P$ $<0.01)$. The ink travelled with a uniform forward progression in all cases with little to-and-fro oscillation. It spread from the point of injection to the upper ampulla and remained thus throughout the observation periods. No ink was transported into the ovarian bursa.

When the ink was injected between 01:00 and 03:00 h of Day 1 (during ovulation), it was rapidly transported to the upper ampulla in the mated and non-mated females. The ink reached the ovarian bursa $159 \mathrm{sec}$ after injection. Within 10-20 min after injection, all the ink had been transported to the ovarian bursa. The times required for the ink to reach the lower and upper ampulla and the ovarian bursa were not significantly different in the mated and non-mated animals. In some preparations, the cumulus mass was observed within the ovarian bursa and could be seen to be picked up by the infundibulum. In no instance did the ink re-enter the oviduct after its expulsion into the ovarian bursa.

A rapid transport of the ink was also observed at 05:00-06:00 h of Day 1 (toward the end of oestrus). Injected ink reached the upper ampulla within approximately $62 \mathrm{sec}$ and all the ink was present there within 7-10 min after injection. Again, no ink was transported into the ovarian bursa.

After ink injection at 07:00-08:00 and 13:00-21:00 h on Day 1 (after oestrus) there was no transport of the ink to the ampullary segment of the oviduct. The to-and-fro movement of the ink, as seen on Days 2 and 3, was noted at this time and the ink again tended to remain as a small bolus. In 4 out of 5 animals examined between 13:00 and 21:00 h on Day 1, half of the ink was expelled into the uterus via the utero-tubal junction during the observation periods.

\section{Discussion}

The present study using India ink as a visible marker has clearly demonstrated that the oviduct exhibits cyclic changes in its movement during the oestrous cycle of the hamster. The isthmic region of the oviduct exhibits consistently active, but not always unidirectional, movements throughout the oestrous cycle. During the periovulatory period both the isthmus and ampulla exhibit an active, co-ordinated movement that propels a fluid suspension towards the ovary. The rapid transport of the ink through the entire length of the oviduct about the time of ovulation is 
quite impressive. The results of these observations should not be interpreted as an indication that the living spermatozoa are transported in a manner identical to that seen for India ink. Spermatozoa, with a distinct shape, motility and specific surface characteristics, may behave differently in the oviduct from ink particles in suspension. The significance of the present study is that the movement of the oviduct is most effectively co-ordinated for the ascent of particles about the time of ovulation.

It is tempting to speculate that the spermatozoa that enter the oviduct are transported to the upper region of the ampulla (the site of fertilization in the hamster) most efficiently during the time of ovulation. Yanagimachi \& Mahi (1976) observed that guinea-pig spermatozoa reside in the lower segment of the oviduct before ovulation and begin to ascend at the time of ovulation and similar observations have been reported for the rat (Shalgi \& Kraicer, 1978) and rabbit (Overstreet, Cooper \& Katz, 1978). The fact that sperm ascent through the oviduct occurs much faster in postovulatory than in preovulatory females (Braden \& Austin, 1954; Yanagimachi \& Chang, 1963; Turnbull, 1966) may be explained by the initiation of an active, co-ordinated movement of the oviduct about the time of ovulation.

One puzzling observation in the present study was that the ink injected into the isthmus shortly before ovulation ascended the oviduct much faster in the mated females than in nonmated animals (see Table 1). We did not observe such a difference in animals several hours before ovulation or during ovulation and we cannot explain this observation at present.

The reason for the enhanced motility of the oviduct during the periovulatory period may be quite complicated. Hormonal factors may well be involved since changes occur in the concentrations of steroid and non-steroidal hormones just before and after ovulation (see Labhsetwar, 1973; Ross \& Vande Wiele, 1974). Direct stimulation of the oviduct by ovulatory products such as the cumulus mass, follicular fluid and ova may occur (Harper, 1973). Nervous involvement also cannot be overlooked (VanDemark \& Hays, 1952). The autonomic nervous system may be implicated since there is adrenergic and cholinergic innervation in the female genital tract (Black, 1974). We are now studying these variables.

This study was supported by a grant from the NIH (HD-03402) and the Ford Foundation. We thank Mrs C. A. Mahi for her assistance in the preparation of the manuscript.

\section{References}

Austin, C.R. (1956) Ovulation, fertilization and early cleavage in the hamster (Mesocricetus auratus). $J l R$. microsc. Soc. 75, 141-154.

Bedford, J.M. (1970) The saga of mammalian sperm from ejaculation to syngamy. In Mammalian Reproduction, pp. 124-182. Eds H. Gibian \& E. J. Plotz. Springer-Verlag, New York.

Bishop, D.W. (1961) Biology of spermatozoa. In Sex and Internal Secretions, 2nd edn, vol. 2, pp. 707796. Ed. W. C. Young. Williams and Wilkins, Baltimore.

Black, D.L. (1974) Neural control of oviduct musculature. In The Oviduct and Its Functions, pp. 65118. Eds A. D. Johnson \& C. W. Foley. Academic Press, New York.

Blandau, R.J. (1969) Gamete transport-comparative aspects. In The Mammalian Oviduct, pp. 129-162. Eds E. S. E. Hafez \& R. J. Blandau. University of Chicago Press.

Blandau, R.J. (1978) Gamete transport in oviducts of rats. Anat. Rec. 190, 593 Abstr.
Blandau, R.J. \& Gaddum-Rosse, P. (1974) Mechanism of sperm transport in pig oviducts. Fert. Steril. 25, 61-67.

Braden, A.W.H. \& Austin, C.R. (1954) The number of sperms about the eggs in mammals and its significance for normal fertilization. Aust. J. biol. Sci. 7, $543-551$.

Clewe, T.H. (1965) Absence of a foramen in the ovarian bursa of the golden hamster. Anat. Rec. 151, 446.

Davajan, F., Nakamura, R.M. \& Kharma, K. (1970) Spermatozoan transport in cervical mucus. Obstet. gynecol. Surv. 25, 1-43.

Halbert, S.A. \& Conrad, J.T. (1975) In vitro contractile activity of the mesotubarium superius from the rabbit oviduct in various endocrine states. Fert. Steril. 26, 248-256.

Harper, M.J.K. (1973) Stimulation of sperm movement from the isthmus to the site of fertilization in the rabbit oviduct. Biol. Reprod. 8, 369-377.

Hartman, C.G. (1957) How do sperms get into uterus? Fert. Steril. 8, 403-427. 
Labhsetwar, A.P. (1973) Pituitary gonadotrophic function (FSH and LH) in various reproductive states. Adv. Reprod. Physiol. 6, 97-183.

Larks, S.D., Larks, G.G., Hoffer, R.E. \& Charison, E.J. (1971) Electrical activity of oviducts in vivo. Nature, Lond. 234, 556-557.

Leonard, S.L. \& Periman, P.L. (1949) Conditions effecting the passage of spermatozoa through the utero-tubal junction of rat. Anat. Rec. 104, 89192.

Moghissi, K.S., Dabich, D., Levine, J. \& Neuhaus, O.W. (1964) Mechanism of sperm migration. Fert. Steril. $15,15-23$.

Norman, R.L. \& Greenwald, G.S. (1972) Follicular history and physiological correlates in the preovulatory hamster. Anat. Rec. 173, 95-108.

Orsini, M.W. (1961) The external vaginal phenomena characterizing the stages of the estrous cycle, pregnancy, pseudopregnancy, lactation and the anestrous hamster, Mesocricetus auratus. Proc. anim. Care Panel 11, 193-206.

Overstreet, J.W., Cooper, G.W. \& Katz, D.F. (1978) Sperm transport in the reproductive tract of the female rabbit. II. The sustained phase of transport. Biol. Reprod. 19, 115-132.

Ross, G.T. \& Vande Wiele, R.L. (1974) The Ovaries. In
Textbook of Endocrinology, pp. 368-422. Ed. R. H. Williams. Saunders, Philadelphia.

Shalgi, R. \& Kraicer, P.F. (1978) Timing of sperm transport, sperm penetration and cleavage in the rat. J. exp. Zool. 204, 353-360.

Strauss, F. (1956) The time and place of fertilization of the golden hamster egg. J. Embryol. exp. Morph. 4, $42-56$.

Turgeon, J. \& Greenwald, G.S. (1972) Preovulatory levels of plasma $\mathrm{LH}$ in the cyclic hamster. Endocrinology 90, 657-662.

Turnbull, K.E. (1966) The transport of spermatozoa in the rabbit doe before and after ovulation. Aust. $J$. biol. Sci. 19, 1095-1099.

VanDemark, N.L. \& Hays, R.L. (1952) Uterine motility responses to mating. Am. J. Physiol. 170, 518-521.

Ward, M.C. (1946) A study of the estrous cycle and breeding of the golden hamster, Cricetus auratus. Anat. Rec. 94, 139-162.

Yanagimachi, R. \& Chang, M.C. (1963) Sperm ascent through the oviduct of the golden hamster and rabbit in relation to the time of ovulation. J. Reprod. Fert. 6, 413-420.

Yanagimachi, R. \& Mahi, C.A. (1976) The sperm acrosome reaction and fertilization in the guinea-pig: a study in vivo. J. Reprod. Fert. 46, 49-54

Received 26 September 1978 